\title{
Efficiency Evaluation of Green Innovation in Chinese Eight Comprehensive Economic Areas Based on Three-stage Malmquist Index
}

\author{
Xueguo Xu, Yanfei Zhou* \\ School of Management, Shanghai University, Shanghai 200444, No. 99, Shangda Road, China
}

Received: 27 July 2020

Accepted: 3 November 2020

\begin{abstract}
Based on the regional panel data of 2011-2018, this investigation firstly employs three-stage Malmquist index to evaluate the green innovation efficiency of Eight Comprehensive Economic Areas in China. Then, according to the different causes of low technology efficiency in different areas, Eight Comprehensive Economic Areas are classified into four categories utilizing pure technology efficiency and scale efficiency matrix. Additionally, the comparison between original and revised Malmquist index is illustrated. The empirical findings are as follows: (1) The green innovation efficiency in the whole country is on the rise. South coast, Northwest and Southwest are ahead of the country. (2) Accelerating the development of technology market and optimizing the industrial structure contribute to the advancement of green innovation efficiency. (3) The green innovation efficiency in the first stage is overestimated due to the overestimated technical efficiency. Furthermore, the fundamental reason for low technical efficiency is low scale efficiency. (4) After excluding the interference of external environment and random factors, the Malmquist index of each region declines. Additionally, the national average value of green innovation efficiency descends from 1.105 to 1.047, and Northwest and Middle Yellow River decreases 5 ranks and increases 3 ranks, respectively.
\end{abstract}

Keywords: green innovation, efficiency, Eight Comprehensive Economic Areas, three-stage Malmquist index, regional difference

\section{Introduction}

The growing population, booming economy, and over exploitation of resources and energies lead to the aggravation of environmental problems. Economic growth has been regarded as refuting the sustainable development for many years [1]. During the past

*e-mail: zyfyibuduo@126.com few years, heavy pollution industries used to be the core of China's industrial economy and greatly contributed to the rapid growth of its economy [2]. However, the accelerating economic development also directly resulted in large amount of energy consumption and serious environmental pollution [3]. The interactions between environmental pollution and economic development become a prominent problem in the process of sustainable development [4]. In a number of resource-based cities, various environmental 
problems are intertwined, such as heavy pollution of environment, black and smelly water, as well as waste siege, restricting the local sustainable development of society, economy and environment [5]. At present, China's economy has changed from a "high-speed growth" to "high-quality development" [6]. Hence, it is imperative to change business mindsets to harness green opportunities and inspire green innovation in response to environmental pressures [7]. In order to emphasize that green development featuring harmonious coexistence between human beings and nature is crucial to realize sustainable development [8], Chinese government has declared the concepts of "ecological civilization", "beautiful China", "innovation, coordination, green, opening and sharing" etc., in response to environmental concerns. These concepts pointed out innovation leading to green development is the only way for high-quality economic development. Green innovation comes into being, and becomes the core mechanism to reconcile the sharp contradiction between ecological environment and economic development [9].

Resource conservation and environment protection embedded in the traditional technology innovation model have become the inevitable requirement of sustainable economic development [10, 11]. Green innovation, also known as eco-innovation and environmental innovation [12], is the addition of environmental factors on the basis of traditional innovation [13]. Moreover, it takes advantages of technology innovation to save natural resources and avert, eliminate, or alleviate the contamination and destruction of the ecological environment[14]. Green innovation is defined as "the creation or implementation of new, or significantly improved, products (goods and services), processes, marketing methods, organisational structures and institutional arrangements which, with or without intent, lead to environmental improvements compared to relevant alternatives [15]. It incorporates technological improvements that save energy, prevent pollution, or enable waste recycling and can include green product design and corporate environmental management [16]. However, the unreasonable proportion of input and output distribution will lead to the low efficiency. As the WICS mentioned, 'the best way of promoting customer interests in a public sector model is by improving the economic efficiency of the industry, and thereby the value of money generated' [17]. Green innovation efficiency is the economic performance of green innovation, which is the "measuring instrument" of innovation quality in view of resources saving and eliminating pollution [18]. It is a critical indicator which reflects the allocation and utilization efficiency of R\&D and natural resources, illustrating the relationship between input and output in the green innovation activities. The higher the green innovation efficiency is, the more matching the input of resource and innovation elements with green performance. Two critical research contents closely related to green innovation efficiency are GTFP and green technology innovation.
Compared with using a single indicator, green total factor productivity (GTFP) combines a host of crucial input and output indicators into a unified analysis framework. It is closer to the real production process than a single indicator. As environmental pollution intensifies, a large quantity of studies have been conducted using different methods to evaluate GTFP [19-22]. Green technology innovation plays a significant role in promoting the natural resources utilization efficiency [23]. It is an effective mean to break out of the constraints of environment, enhance the competitiveness of enterprises and achieve the upgrading of industrial structures so as to promote high-quality economic growth [24]. In addition, it is committed to pursuing the "win-win" development pattern of environment and economy [25, 26].

Environmental regulation (ER) is a crucial factor influencing green innovation. Scholars mainly focus on whether it is conduce to promote green innovation. Zhang and $\mathrm{Xu}$ [27] supposed that governments usually enact more stringent ER to stimulate enterprises' green innovations. $\mathrm{Bi}$, et al. [28] reported that ER showed a positive influence on low-carbon technological innovation performance. For some firms with high pollution emission, ER can promote GTFP through increasing market concentration and building green market entry barriers [29]. However, quite a few scholars found the opposite evidence [30-34]. In addition, Feng, et al. [35] pointed out that although ER had an essential influence on green innovation efficiency, significant differences in the impact mechanism and process of different ERs were observed. Therefore, factors such as technology introduction, R\&D investment, as well as enterprise scale should also be included, so as to better understand the mediating effect of ER on green innovation efficiency.

In general, there are two main methods of measuring green innovation efficiency: the parametric method, using Stochastic Frontier Analysis (SFA) method [36, 37] and the non-parametric method, using Data Envelopment Analysis (DEA) method [24, 38]. However, the SFA can only measure the efficiency of a single output, and traditional DEA just deals with static data. Additionally, they cannot eliminate the influence of external environment and random disturbance on efficiency value which will lead to the deviation and incompleteness of calculation results. Therefore, more researchers have begun employing Malmquist index [39-42] and three-stage DEA model [5, 43, 44] to evaluate efficiency separately. The former can deal with dynamic data and the latter has advantages in eliminating the influence of external environment and random disturbance. However, the two methods have their own shortcomings in measuring efficiency. In this regard, the three-stage Malmquist index synthesizes the advantages of two methods, enabling the actual efficiency to be calculated over multi-periods.

It is well known that China consists of eastern, central and western three parts. Nowadays, the Eight 


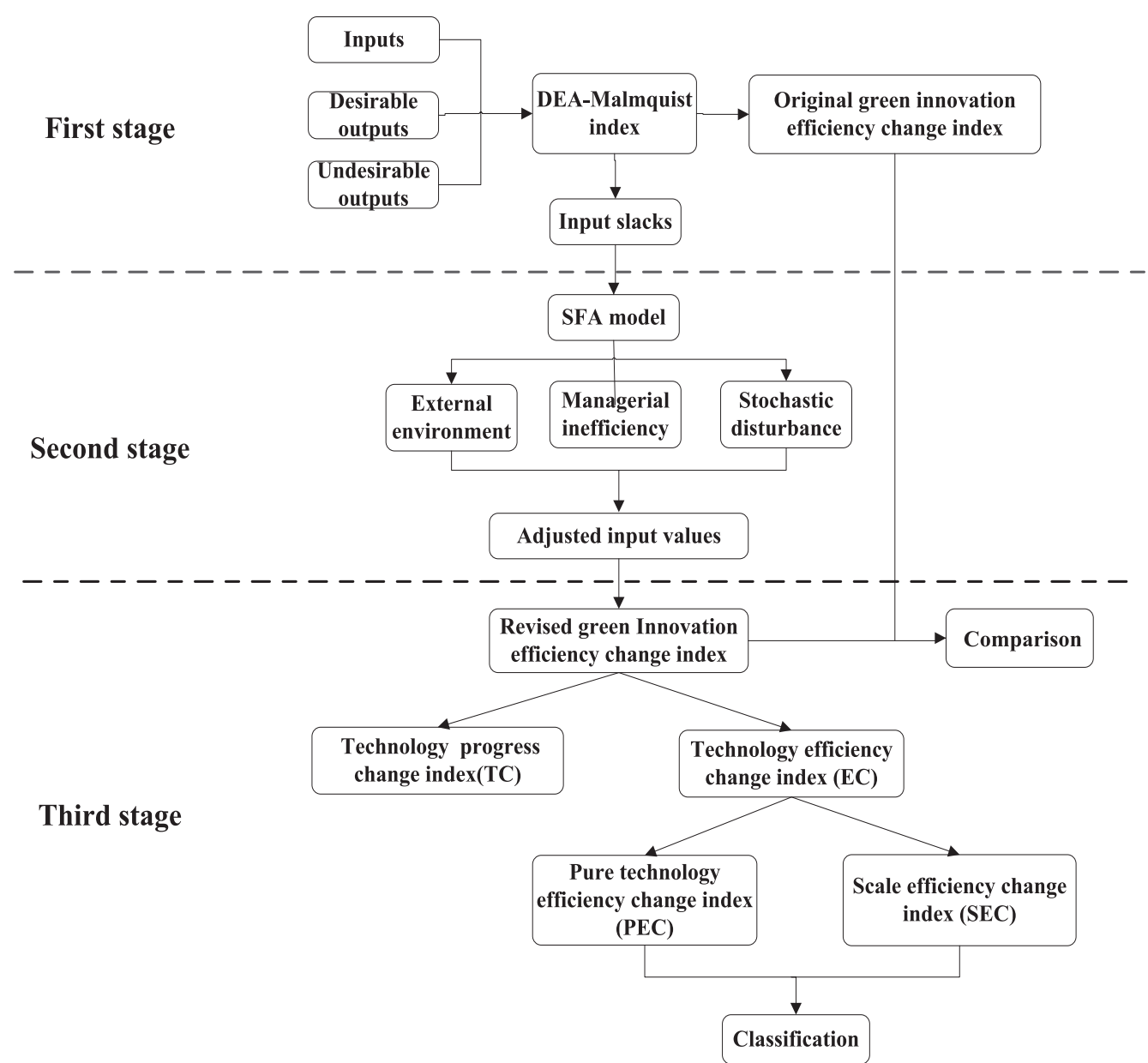

Fig. 1. Methodological framework of the study.

Comprehensive Economic Areas has become a new research object for scholars. The regional coordinated development in Eight Comprehensive Economic Areas as the core strategy is an important support for the overall development strategy in the new era [45]. However, the aforementioned studies were mainly conducted at the province $[2,46]$ and industry level $[28,35,47]$, noticeably missing from Eight Comprehensive Economic Areas. In order to fill these gaps, we incorporate the "innovation failure" and "environmental pollution" factors into the unexpected output, firstly employed dynamic three-stage Malmquist index to calculate the green innovation efficiency in Eight Comprehensive Economic Areas excluding external environment and random interference factors. It is conducive to clarify the regional differences of green innovation and provide reference for formulating reasonable regional coordinated development policies.

\section{Methodology}

DEA is a nonparametric prediction frontier of observation data constructed by using linear programming method proposed by Charnes, Cooper and Rhodes [48]. On this basis, the relative efficiency of several similar decision-making units (DMUs) with multiple inputs and outputs is calculated [49]. Then, Banker et al. put forward BCC model in 1984 and decomposed the technology efficiency change index $(E C)$ into pure technology efficiency change index $(P E C)$ and scale efficiency change index (SEC). The Malmquist index is an essential method to measure the efficiency of dynamic DEA, which is expressed by the ratio of distance function. Fig. 1 shows the methodological framework of this study.

First stage: DEA-Malmquist index

Färe, et al. [50] first combined the Malmquist index with DEA to construct the DEA-Malmquist index, which applied widely to calculate the productivity. The formula is as follows:

$$
\begin{aligned}
& M_{i}\left(x^{t+1}, y^{t+1}, x^{t}, y^{t}\right)=\left|\frac{D_{0}^{t}\left(x^{t+1}, y^{t+1}\right)}{D_{0}^{t}\left(x^{t}, y^{t}\right)} \times \frac{D_{0}^{t+1}\left(x^{t+1}, y^{t+1}\right)}{D_{0}^{t+1}\left(x^{t}, y^{t}\right)}\right|^{1 / 2}
\end{aligned}
$$

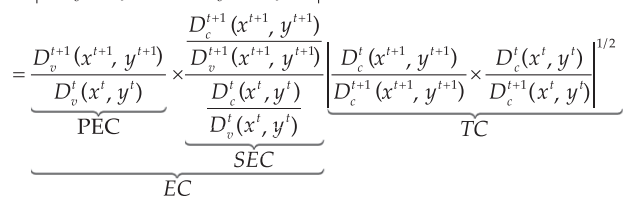


In Eq. (1), $\left(x^{t}, y^{t}\right)$ and $\left(x^{t+1}, y^{t+1}\right)$ are the input and output vectors of $t$ period and $(t+1)$ period respectively; $D_{0}^{t}\left(x^{t}, y^{t}\right)$ and $D_{0}^{t+1}\left(x^{t+1}, y^{t+1}\right)$ are the distance functions; $D_{0}^{t}\left(x^{t+1}, y^{t+1}\right)$ and $D_{0}^{t}\left(x^{t}, y^{t}\right)$ denote the input differences compared with the production front in the mixing period respectively. If $M_{i}>1$, the efficiency increases, and vice versa. $E C$ represents the ability to obtain the maximum output, which can be further decomposed as $P E C$ and $S E C$. When $E C>1$, technology efficiency improves; otherwise, technology efficiency declines. $P E C>1$ shows that application degree of technology increases. On the contrary, the opposite is true. $S E C>1$ denotes that scale efficiency enhances, and vice versa. $T C>1$ indicates that technological progress; otherwise, there is a technical retreat.

Second stage: Input adjustment of the SFA model

The detailed steps are as follows:

\section{Calculation of Input Slack}

BCC model is used to calculate the input slack $S_{n k}$ of each $D M U$, that is, the difference between the original input and the target input.

\section{Construction of the SFA Regression Model}

The models of input slack $S_{n k}$ and environment variables are as follows:

$$
S_{n i}=f\left(Z_{i} ; \beta_{n}\right)+v_{n i}+\mu_{n i}, i=1,2, \ldots, I ; n=1,2, \ldots N
$$

...where $S_{n i}$ denotes the slack variable for the $n$-th input of the $D M U_{i}$. In general, $f\left(Z_{i} ; \beta_{n}\right)=Z_{i} \beta_{n}, f\left(Z_{i} ; \beta_{n}\right)$ represents the influence of the environmental variable on the input slack; $Z_{i}$ is the $i$-th environment variable, $\beta_{n}$ is the parameter vector; $v_{n i}$ and $\mu_{n i}$ are independent and the sum of them is the mixed error term; $v_{n i}$ denotes the random error term, $v_{n i} \sim N\left(0, \sigma_{v}^{2}\right) . \mu_{n i}$ represents management inefficiency, $\mu_{n i} \sim N^{+}\left(0, \sigma_{u}^{2}\right)$. If $\mu_{n i} \geq 0$, management is inefficient. Set $\gamma=\frac{\sigma_{u}^{2}}{\sigma^{2}+\sigma_{v}^{2}}, \gamma$ approaching 1 indicates that the $\mu_{n i}$ is the dominant factor, that is, SFA model is applicable for estimation; whereas $\gamma$ approaching 0 indicates that $v_{n i}$ is the dominant factor.

\section{Adjusting Input Variables}

To achieve this, Frontier 4.1, written by Professor Tim Coelli, is a software to estimate the stochastic frontier cost model and stochastic frontier production model by maximum likelihood method. In this study, it is used to estimate the value of $\sigma^{2}, \gamma, \beta_{n}$, and the input variable is adjusted according to the SFA regression result. Fried, et al. [51] pointed out that the disintegration approach proposed by Jondrow, et al. [52] can be used as a reference to achieve the conditional estimation of management inefficiency:

$$
\begin{gathered}
E\left[v_{n i} \mid v_{n i}+u_{n i}\right]=S_{n i}-Z_{i} \beta_{n}-E\left[u_{n i} \mid v_{n i}+u_{n i}\right] \\
i=1,2, \ldots, I ; n=1,2, \ldots N
\end{gathered}
$$

The random error term is separated from the mixed error term. The conditional expectation value of administration inefficiency term $u_{n i}$ can be computed as:

$$
E\left[u_{n i} \mid v_{n i}+u_{n i}\right]=\frac{\sigma \lambda}{1+\lambda^{2}}\left[\frac{\varphi\left(\frac{\varepsilon_{i} \lambda}{\sigma}\right)}{\phi\left(\frac{\varepsilon_{i} \lambda}{\sigma}\right)}+\frac{\varepsilon_{i} \lambda}{\sigma}\right]
$$

Among which, $\lambda=\frac{\sigma_{u}}{\sigma_{v}}, \varepsilon_{i}=v_{n i}+u_{n i}, \varphi$ and $\phi$ represents the probability frequency function and the cumulative distribution function for standard normal distribution respectively. The elaborated mathematical procedure can be referred to references $[2,51]$. Then, the adjusted formula is as follows:

$$
\begin{gathered}
\mathrm{X}_{n i}^{\prime}=\mathrm{X}_{n i}+\left[\max \left(Z_{i} \beta_{n}\right)-Z_{i} \beta_{n}\right]+\left[\max \left(v_{n k}\right)-v_{n k}\right], \\
i=1,2, \ldots, I ; n=1,2, \ldots N
\end{gathered}
$$

...where $\mathrm{X}_{n i}^{\prime}$ denotes the adjusted input value after the SFA regression, $X_{n i}$ denotes the original input value. $\left[\max \left(Z_{i} \beta_{n}\right)-Z_{i} \beta_{n}\right]$ is the adjustment value of external environmental factors, $\left[\max \left(v_{n k}\right)-v_{n k}\right]$ is the adjusted value of random error. All DMUs are adjusted to similar "luck".

Third stage: Revised Malmquist index

The original input not reached the actual level are replaced by the adjusted input which based on the SFA regression analysis results, while the output is unchanged. The same calculate method is used again for evaluating the efficiency. Considering the influence of external environmental factors and stochastic disturbance have been eliminated, the result is more objective and accurate.

\section{Data and Variables}

\section{Data Sources}

According to the different conditions of social and economic development, the Development Strategy and Regional Economic Research Department of the Development Research Center of the State Council put forward the division method of Eight Comprehensive Economic Areas (Table 1) [45]. All data used are derived from China Statistical Yearbook [53], the China Science and Technology Statistical Yearbook [54] and China Environmental Statistical Yearbook [55] in 2012-2019.

\section{Input and Output Indicators}

Innovation efficiency is measured by innovation input and output. Human resources, financial resources 
Table 1. The Scope of Eight Comprehensive Economic Areas.

\begin{tabular}{|c|c|}
\hline Comprehensive economic areas & Regional scope \\
\hline Northeast & Liaoning, Jilin, Heilongiang \\
\hline North coast & Beijing, Tianjin, Hebei, Shandong \\
\hline East coast & Shanghai, Jiangsu, Zhejiang \\
\hline South coast & Fujian, Guangdong, Hainan \\
\hline Middle Yellow River & Shanxi, Shaanxi, Henan, Inner Mongolia \\
\hline Middle Yangtze River & Hubei, Hunan, Jiangxi, Anhui \\
\hline Southwest & Yunnan, Guizhou, Sichuan, Chongqing, Guangxi \\
\hline Northwest & Gansu, Qinghai, Ningxia, Xinjiang \\
\hline
\end{tabular}

and energy are the main input factors of green innovation, which are expressed by full-time equivalent of $R \& D$ personnel, internal expenditure of $R \& D$ funds and comprehensive energy consumption respectively. In view of the time lag in green innovation output, we set the delay for one years. Besides, we choose the perpetual inventory method to estimate the capital stock. For monetary variables, 2010 is picked as the benchmark year to eliminate the influence of price factors [42].

For output variables, the number of patent granted and the new product sales revenue are selected as the desirable output, and the comprehensive two indicators can better reflect the innovation efficiency. For the undesirable output variables, in view of the purpose of innovation is to obtain excess profits, and whether obtain economic profits or not can be a sign of success or failure of innovation. "Innovation failure" has a negative impact on the normal repayment of loans for enterprises, and in order to alleviate financial pressure, they may apply to commercial banks for additional loans. If they cannot be compensated by profits, they will form non-performing loans [56]. Hence, the "innovation failure" can be characterized by the "yearon-year ratio of the amount of non-performing loans of commercial banks". Besides, the sum of the three indicators (total discharge of industrial wastewater, $\mathrm{SO}_{2}$ and industrial solid waste) are measured to investigate the "environmental pollution" factors comprehensively. In this study, the Entropy method [57] is employed to integrate the three emission indicators into the environmental pollution index, so as to assess the undesirable output.

\section{External Environmental Variables}

The traditional Malmquist index attributes all deviations from the efficiency frontier to management inefficiency, and ignores the influence of external environment and random factors. This is obviously unreasonable, because efficiency is not only related to input and output variables, but also affected by external factors such as the level of economic development, the degree of economic openness and ER etc. The selected variables of green innovation influencing factors need to meet the "separation hypothesis," namely, the factors influence the green innovation efficiency while the selected samples cannot be changed subjectively in a short time [14]. We suppose that the following factors have different degree influence on green innovation efficiency.

\section{Economic Development (ED)}

In general, areas with higher level of $E D$ present more strength in technology innovation and application. According to the Kuznets curve, with the improvement of per capita income, the demand for improving environment will continue to rise [58]. Thus, these cities tend to invest more in resources conservation and environmental protection, so as to promote the green innovation efficiency. Therefore, we regard $E D$ as an external factor of green innovation efficiency and per capital GDP $(P G D P)$ is picked as the representative indicator.

\section{Foreign Direct Investment (FDI)}

The degree of economic openness is expressed by the total investment of foreign-funded enterprises at the end of the year. Relevant theories mainly include two aspects: on one hand, the "pollution heaven hypothesis" holds that developed countries tend to transfer energy intensive pollution sectors to developing countries, thereby reducing the green innovation efficiency of developing countries [59]. On the other hand, FDI is conducive to enhance technological efficiency and promote productivity through technological spillover [29].

\section{Environmental Regulation (ER)}

Porter M.E., van der Linde C. [60] pointed out that proper $E R$ contributes to enhancing resource utilization efficiency, promoting enterprises' technological innovation. $E R$ is also associated with green innovation 
investments [61]. There was evidence of a "winwin" prospect between production increase as well as emission reduction as a result of environmental constraints [62]. It is measured by investment in industrial pollution control, which plays a guiding role in reducing environmental pollution and promoting green innovation. The more effective the $E R$, the lower environmental pollution index, and higher green innovation efficiency.

\section{Technology Market Development (TMD)}

Technology market is a bridge connecting capital, labor force and information market, which is of great significance to realize the flow and optimal allocation of technology and promote the diffusion of green technology. The more transactions in the technology market, the faster the technology flow and advance, and the greater possibility of promoting the green innovation efficiency.

\section{Industrial Structure (IS)}

IS reflects the growth agency and composition of regions' economy, represented by the ratio of output value of the tertiary industry in GDP. On the one hand, the higher the ratio of the tertiary industry, the lower the ratio of the second industry, the lower the pressure of energy consumption and environmental pollution, and the higher green innovation efficiency [63]. On the other hand, the scientific research and technical service industry, environment and public facilities management industry in the tertiary industry can provide strong support for green innovation.

\section{Results}

\section{Traditional Malmquist Index Analysis}

Table 2 conveys that the Malmquist index of Eight Comprehensive Economic Areas is greater than 1 during the investigation period, indicating that the green innovation efficiency in the whole country shows an upward trend, and the annual growth rate is $10.5 \%$. Regionally, the ranking of green innovation efficiency is as follows: South coast (1.199) $>$ Northwest (1.168)> Southwest (1.159)>Middle Yangtze River (1.094)> Middle Yellow River (1.080)>Northeast (1.069)>East coast (1.050) $>$ North coast (1.024).

From the perspective of $E C$, the average value is 1.004 during the whole investigation period, indicating that green innovation in Eight Comprehensive Economic Areas approaches to the production frontier. But the technology efficiency rises slowly. Regionally, Southwest has the highest level (1.029). According to the formula (1), EC can be further divided into $P E C$ and $S E C$. Thus, the reasons for the change of technology efficiency can be analyzed from two aspects. On the one hand, the national average of $P E C$ is 1.000 , which indicates that the application degree of green innovation technology remains unchanged. On the other hand, $S E C$ increases only by $0.4 \%$ annually, implying that the green innovation scale efficiency is optimized but the growth is relatively slow. Hence, the change of $E C$ is dominated by $S E C$.

During the whole investigation period, the national average of $T C$ is 1.102 . That is to say, the green innovation technology has made progress. Moreover, $T C$ is larger than $E C$, indicating that $T C$ is dominant factor of Malmquist index.

\section{Regression Analysis of SFA Model}

According to the constructed SFA model of input slack variables and environment variables, it includes five dependent variables and three independent variables. Table 3 shows the regression result.

The $L R$ values are all higher than the critical value of $1 \%$ significance level in the unilateral generalized likelihood ratio test (5.41) and pass the significance test, illustrating the robustness of the SFA model. The values of $\gamma$ are all higher than 0.6 and pass the significance test at the $1 \%$ level, implying the existence of management

Table 2. The Malmquist Index and its Decomposition of Green Innovation Efficiency in Eight Comprehensive Economic Areas.

\begin{tabular}{|c|c|c|c|c|c|}
\hline Comprehensive economic areas & EC & TC & PEC & SEC & Malmquist \\
\hline Northeast & 1.023 & 1.045 & 1.018 & 1.006 & 1.069 \\
\hline North coast & 0.972 & 1.054 & 0.997 & 0.975 & 1.024 \\
\hline East coast & 1.000 & 1.050 & 1.000 & 1.000 & 1.050 \\
\hline South coast & 1.002 & 1.197 & 0.998 & 1.004 & 1.199 \\
\hline Middle Yellow River & 1.007 & 1.076 & 0.987 & 1.020 & 1.080 \\
\hline Middle Yangtze River & 1.007 & 1.087 & 0.998 & 1.010 & 1.094 \\
\hline Southwest & 1.029 & 1.128 & 1.008 & 1.021 & 1.159 \\
\hline Northwest & 0.992 & 1.178 & 0.998 & 0.994 & 1.168 \\
\hline National average & 1.004 & 1.102 & 1.000 & 1.004 & 1.105 \\
\hline
\end{tabular}


Table 3. SFA Regression Analysis Results.

\begin{tabular}{|c|c|c|c|}
\hline $\begin{array}{ll}\text { Environmental variables } & \text { Slack variables } \\
\end{array}$ & $\begin{array}{l}\text { Full time equivalent for } \\
\text { R\&D personnel }\end{array}$ & $\begin{array}{l}\text { Internal expenditure stock } \\
\text { of R\&D funds }\end{array}$ & $\begin{array}{l}\text { Total energy } \\
\text { consumption }\end{array}$ \\
\hline Constant & $\begin{array}{c}-12231.15^{* * * *} \\
(-6.11)\end{array}$ & $\begin{array}{c}-620341.17 * * * \\
(-32.32)\end{array}$ & $\begin{array}{c}-757.69 * * \\
(-3.01)\end{array}$ \\
\hline PGDP & $\begin{array}{l}35048.37 * * * \\
(105.29)\end{array}$ & $\begin{array}{l}750077.32 * * * \\
(3.10)\end{array}$ & $\begin{array}{c}924.43 * * * \\
(13.52)\end{array}$ \\
\hline FDI & $\begin{array}{l}4287.84 * * * \\
(29.74)\end{array}$ & $\begin{array}{l}140993.86^{* * *} \\
(2.91)\end{array}$ & $\begin{array}{c}-1549.19 \\
(-1.41)\end{array}$ \\
\hline ER & $\begin{array}{l}703.50 \\
(1.44)\end{array}$ & $\begin{array}{l}404800.78^{* * * *} \\
\quad(12.54)\end{array}$ & $\begin{array}{l}89.31 \\
(0.16)\end{array}$ \\
\hline TMD & $\begin{array}{c}-23084.87 * * * \\
(-373.31)\end{array}$ & $\begin{array}{l}-721761.61 * * * \\
(-14.65)\end{array}$ & $\begin{array}{l}-1262.94 * * * \\
(-10.67)\end{array}$ \\
\hline IS & $\begin{array}{c}-3417.10 * * * \\
(-4.20)\end{array}$ & $\begin{array}{c}375338.24 * * * \\
(8.51) \\
\end{array}$ & $\begin{array}{r}693.49 \\
(1.23) \\
\end{array}$ \\
\hline$\sigma^{2}$ & $0.85 \mathrm{E}+09$ & $0.68 \mathrm{E}+12$ & $0.15 \mathrm{E}+08$ \\
\hline$\gamma$ & 0.75 & 0.82 & 0.84 \\
\hline Log likelihood function & -1675.57 & -2157.86 & -1350.26 \\
\hline LR test of the one-sided error & 62.28 & 92.92 & 93.45 \\
\hline
\end{tabular}

Note: (1) The number in brackets demonstrate $t$-statistics of the estimated parameters. $(2) * * *, * *$, and * indicate significance at $\mathrm{p}<0.01, \mathrm{p}<0.05$, and $\mathrm{p}<0.10$, respectively.

inefficiency. In addition, the regression results show that most coefficients passed the $t$-value estimation, indicating the reliability of the results.

If the regression coefficient of external environmental variables is positive, that means an increase of the variable will add the slack value of the input and reduce the output, so as to result in the waste of resources, that is, the increase of the environmental variables has a negative effect on green innovation efficiency. In particular, the influence of each environment variable on three input slack variables are presented as follows:

(1) The impact of ED. The regression results show that $P G D P$ presents a positive relationship with three input slacks $(\mathrm{r}=35048.37, \mathrm{r}=750077.32, \mathrm{r}=924.43$; $\mathrm{p}<0.01$ ), indicating that raising the economic level will add the input slacks, resulting in input waste and output decline, which is contrary to the expected results. However, it also reflects that there is a large amount of redundancy in current $R \& D$ and energy input. The management inefficiency leads to the utilization of innovative resources and energy is in the stage of "input driven development".

(2) The relationship among economic openness, the input slack of R\&D personnel's full-time equivalent and internal expenditure stock of $R \& D$ funds is positive $(r=4287.84, r=140993.86)$ and significant $(p<0.01)$. While the total energy consumption is the nonsignificant slack variable. This finding implies that, at present, the more open of economy, the more waste of R\&D personnel and funds, which can bring unfavorable impacts on green innovation efficiency. Comparatively, the impact of economic openness on energy consumption is not significant.

(3) The impact of $E R$. From the regression results listed in Table 3, the impact of ER on the input slack of R\&D personnel's full-time equivalent and total energy consumption is insignificant, while $E R$ is positively correlated with internal expenditure stock of $R \& D$ funds $(r=404800.78)$. It means that the stricter the enforcement of $E R$, the lower utilization level of $R \& D$ funds, that is, regional environmental policies have not played a good role in improving the utilization rate of R\&D funds.

(4) It is also observed that the interaction among $T M D$ and three input slacks is negative $(\mathrm{r}=-23084.87$, $\mathrm{r}=$-721761.61, $\mathrm{r}=-1262.94)$ and significant $(\mathrm{p}<0.01)$, indicating that the increase of transactions in technology market will facilitate technology flow and technology progress, and improve the utilization ratio of $R \& D$ resources and natural resources.

(5) Finally, the coefficient of $I S$ with regard to the slack of R\&D personnel's full-time equivalent is negative $(r=-3417.101)$ while the effect on the internal expenditure stock of R\&D funds is positive $(r=375338.24)$. The effect on the total energy consumption is not significant. This result indicates that an increase in the proportion of tertiary industry contributes to the improvement of the utilization efficiency of R\&D personnel. Moreover, the current $I S$ is not reasonable, which easily lead to a huge waste of R\&D funds and energy. 


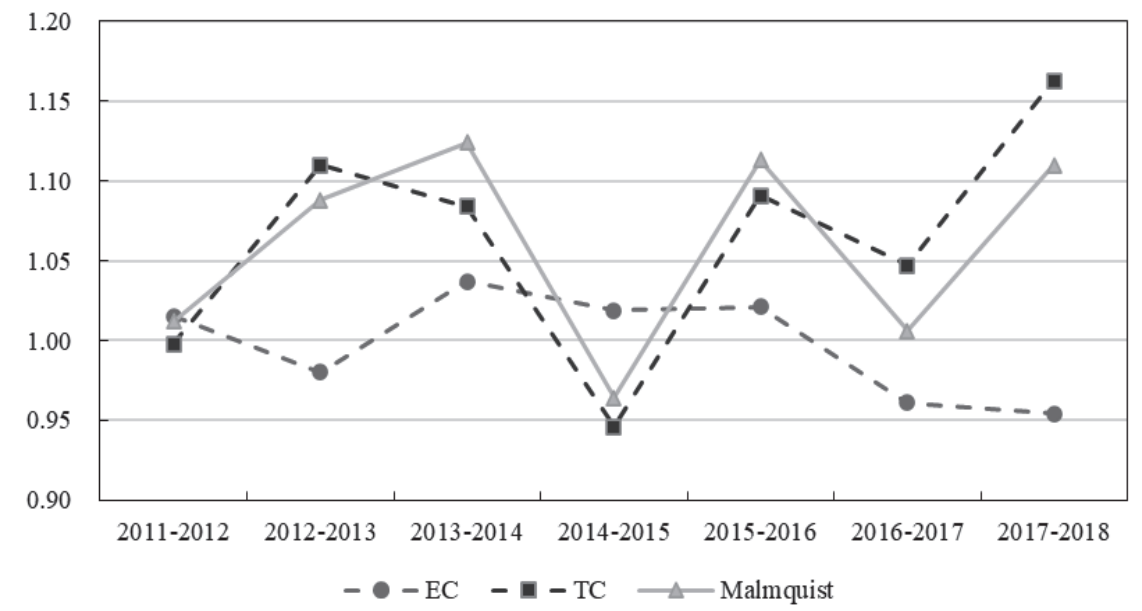

Fig. 2. The real green innovation efficiency from 2011 to 2018 .

\section{Revised Malmquist Index Analysis}

The real green innovation efficiency in Eight Comprehensive Economic Areas from 2011 to 2018 calculates are depicted in Fig. 2. In terms of time series, it increases in wave from 1.1012 to 1.110 . 2013-2014 achieves the highest value of 1.124, followed by 2015-2016 (1.113) and 2017-2018 (1.110). The revised Malmquist index in 2014-2015 is less than 1 (0.964), implying that green innovation efficiency declines. Besides, the fluctuation trend of TC and Malmquist is similar, which indicates that green innovation efficiency is mainly determined by technology progress. The values of $E C$ in 2012-2013, 2016-2017 and 2017-2018 are less than 1 , implying that technology efficiency plays a restraining role.

Table 4 shows that the revised Malmquist index and its decomposition in Eight Comprehensive Economic Areas. In order to explore reasons for low $E C$ index, we divide Eight Comprehensive Economic Areas into four categories utilizing $P E C-S E C$ matrix (Fig. 3).

(1) SEC promote and PEC weaken. This group is represented by Northeast. The role of $S E C$ is very weak, and $P E C$ has a restraining effect on $E C$. It can be seen that the level of technology application in Northeast is in a declining stage, indicating that after implementing the "economic revitalization plan", the proportion of high-tech industry and modern service industry in Northeast is still low. In addition, as a resource-based region, Northeast will inevitably encounter the problems of resource depletion and environmental pollution. Therefore, for Northeast, opportunities to improve $E C$ primarily lie in enhancing $P E C$ by advancing technical innovation and application in production process, managing the product life cycle from the choice of raw materials to the recycling and reuse of waste.

(2) PEC promote and SEC weaken. This group includes North coast, Middle Yangtze River and Northwest. EC in these areas is driven by $P E C$, and the irrational proportion of input-output leads to the reduction of SEC. Taking Beijing as an example, although it has an absolute advantage in innovation resources investment, high-end talent introduction and industrial agglomeration, the scale of green innovation in North coast is still in an invalid state.

Table 4. The Revised Malmquist Index and its Decomposition of Green Innovation in Eight Comprehensive Economic Areas.

\begin{tabular}{|c|c|c|c|c|c|}
\hline Comprehensive economic areas & EC & TC & PEC & SEC & Malmquist \\
\hline Northeast & 0.992 & 1.051 & 0.983 & 1.009 & 1.043 \\
\hline North coast & 0.979 & 1.043 & 1.005 & 0.975 & 1.021 \\
\hline East coast & 0.989 & 1.053 & 0.997 & 0.992 & 1.041 \\
\hline South coast & 0.985 & 1.097 & 0.999 & 0.986 & 1.080 \\
\hline Middle Yellow River & 0.987 & 1.077 & 0.996 & 0.991 & 1.062 \\
\hline Middle Yangtze River & 0.984 & 1.064 & 1.002 & 0.982 & 1.047 \\
\hline Southwest & 1.012 & 1.049 & 1.003 & 1.009 & 1.061 \\
\hline Northwest & 0.977 & 1.049 & 1.001 & 0.976 & 1.024 \\
\hline National average & 0.988 & 1.060 & 0.998 & 0.990 & 1.047 \\
\hline
\end{tabular}




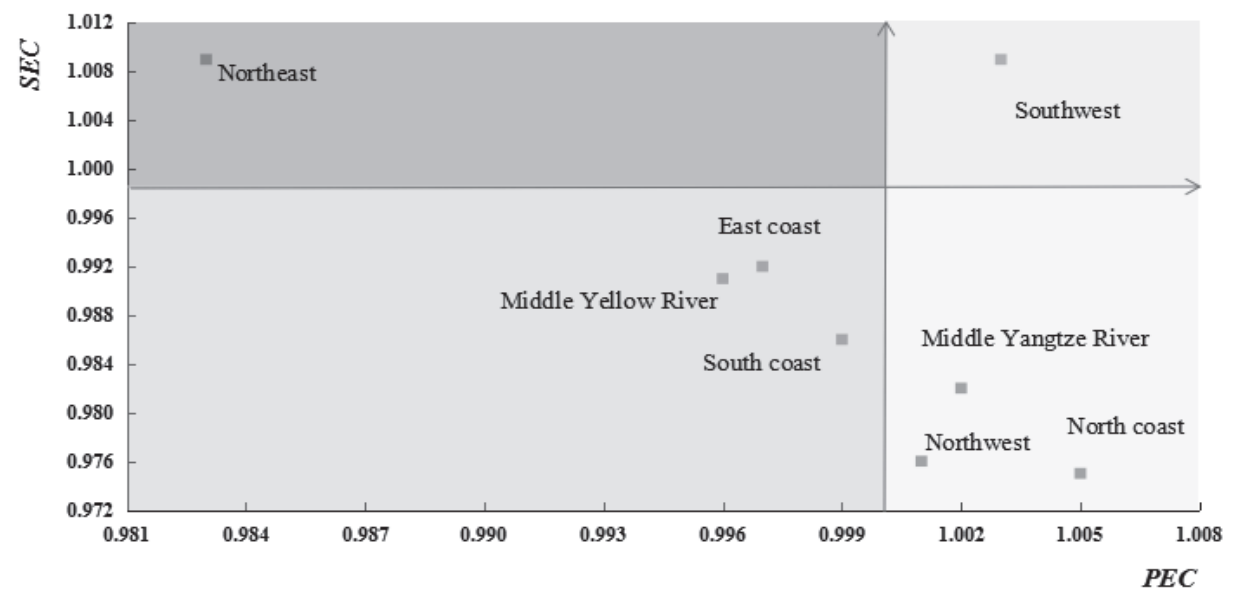

Fig. 3. The scatter plots of green innovation efficiency between PEC and SEC in Eight Comprehensive Economic Areas.

This phenomenon reflects that the radiation effect of Beijing on its surrounding cities is not obvious, and the overall scale advantage has not been formed. For Middle Yangtze River, it belongs to a typical carbonbased energy economy, coupled with the extensive development of urban industrialization and the rapid expansion of urban population, it inevitably suffers from serious environmental pollution and resource depletion. As a result, the green innovation efficiency drops. As the gathering place of underdeveloped provinces, Northwest mainly undertakes the industrial transfer from developed provinces. In the process of industrial transfer, on the one hand, the investment and utilization of innovation resources has been boosted. On the other hand, the western provinces experience more challenging ecological pressures, such as the weak consciousness of resource conservation and lack of independent innovation, resulting in excessive consumption of energy and environmental advantages. Consequently, green innovation is at the phase of diseconomy scale.

(3) $P E C$ and $S E C$ weaken jointly. This group includes three areas (East coast, South coast and Middle Yellow River). These regions are located in the coast areas which have a large number of industrial enterprises, causing a great deal of pollution emissions and serious damage to the environment. The green innovation technology in these areas is not applied to the maximize output or realize coordinated development between the economy and ecological environment. At the same time, low SEC may be associated with the inferiority in the investment of scientific and technological innovation as well as the resource allocation efficiency. Generally, the coast areas have better infrastructure, more advanced technologies and stringent $E R$, contributing to improving resource utilization and reducing pollutant emissions [62], so as to promote green innovation efficiency. However, this outcome contradicts the present result. Middle Yellow River covers the major energy provinces while undertakes the external industry transfer. The calculated result reflects that it is similar to East coast and South coast, $P E C$ and $S E C$ hinder the $E C$ jointly, resulting in the unsatisfactory green innovation efficiency.

(4) PEC and SEC promote jointly. The only region is Southwest. Compared with other regions, Southwest has advantages in the use of green innovation technology and scale efficiency. In the 2018 Evaluation Report on Regional Scientific and Technological Innovation, Chongqing and Sichuan became regional scientific and technological innovation centers in the western region. At the same time, Chongqing ranked first in the high and new technology industrialization index. This benefited from high resources endowments, ecofriendly environment and obvious advantage for scale economy. Hence, it can development rapidly and become the highlight of regional green innovation.

\section{Comparison of Original and Revised Malmquist Index}

Fig. 4 illustrates that the revised Malmquist index declines after eliminating the influence of environmental factors and stochastic disturbance. The national average value of Malmquist index decreases from 1.105 to 1.047 , indicating the green innovation efficiency is greatly affected by external environmental factors, and the original green innovation efficiency is overestimated. This matches our expectations. Therefore, optimizing the external environment is conducive to the improvement of green innovation efficiency. Regionally, the ranking of green innovation efficiency is as follows: South coast (1.080)>Middle Yellow River (1.062) $>$ Southwest (1.061) $>$ Middle Yangtze River (1.047)>Northeast (1.043)>East coast (1.041) $>$ Northwest (1.024) $>$ North coast (1.021). Among which, Northwest decreases 5 ranks and Middle Yellow River increases 3 ranks, respectively. Northeast and East coast both decrease 1 rank, and the rest regions maintain unchanged. This result may be related to the financial resources in Northwest and Middle Yellow River are greatly influenced by the central government's transfer 


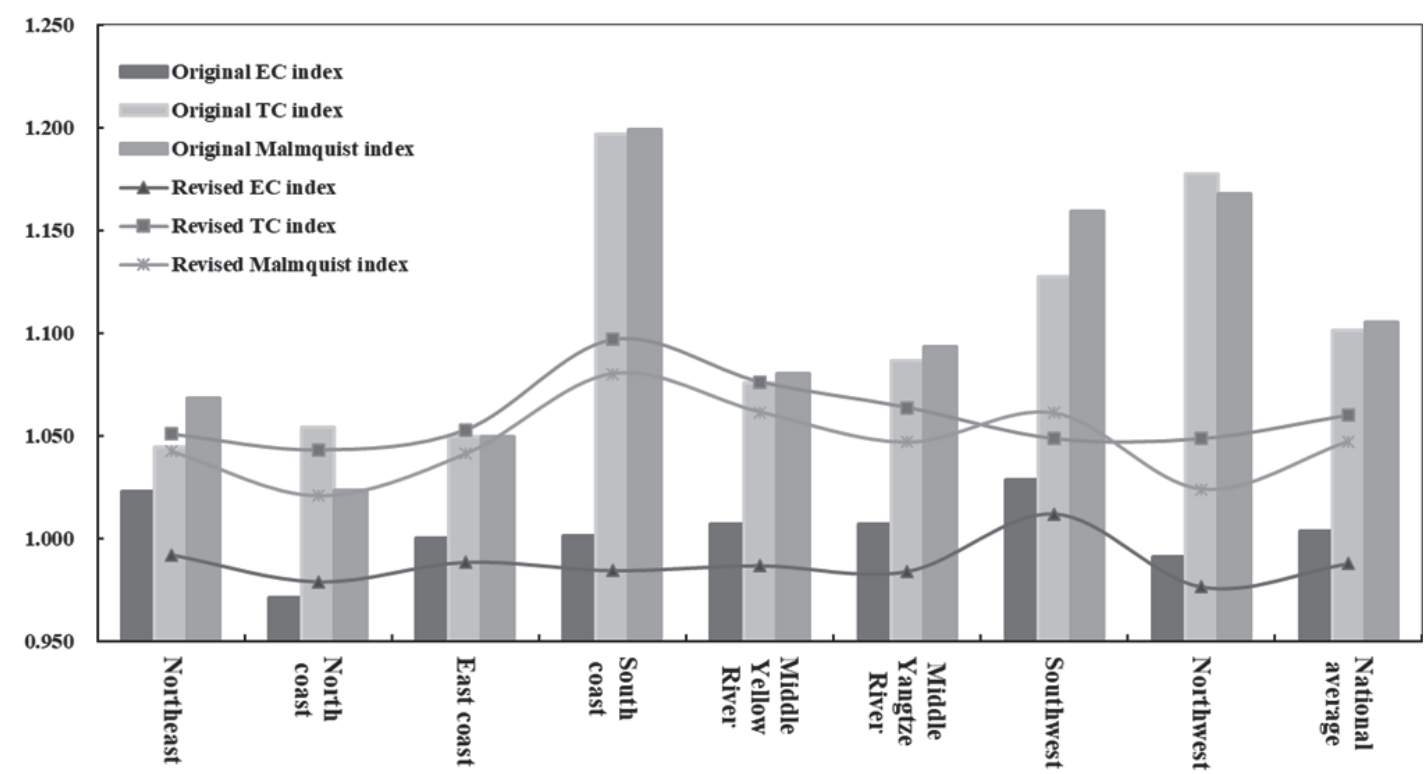

Fig. 4. Comparison of original and revised green innovation efficiency in Eight Comprehensive Economic Areas.

payment policy, and the impacts of other environmental factors are relatively weak. Therefore, the slight change of resource input can lead to the obvious fluctuation of green innovation efficiency in two regions.

The revised $E C$ index declines except for North coast, indicating that the $E C$ obtained before adjustment is overestimated and greatly affected by five environmental variables. In addition, the revised $E C$ index is greater than 1 only in Southwest, implying that the green innovation in Southwest approaches to the production frontier, and green innovation technology efficiency has an upward trend. For most regions, $E C$ is overestimated. In fact, it presents the tendency of declining, showing that there are still many deficiencies in optimization of system, organization and management.

The values of revised $T C$ index in Eight Comprehensive Economic Areas are all greater than 1 , that is to say, the possibility boundary of green innovation production in each region moves outward and green innovation technology advances. By comparing the original and revised $T C$ index, it is found that $T C$ boosts in Northeast, East coast and Middle Yellow River and drops in rest areas. Notably, if the impacts of environmental factors are not considered, TC in these areas will be underestimated, resulting in the deviation of the analysis results.

\section{Discussion}

In terms of traditional Malmquist index analysis, South coast is ahead of the whole country, followed by Northwest and Southwest, which indicates that benefits from the national "western development strategy", Northwest and Southwest have not only enhanced the quality and quantity of innovation, but also maintains an undamaged ecological environment. This phenomenon could be attributed to R\&D probably results in a positive relationship with green innovation and facilitates the technological adaptations needed to evolve clean technologies [61]. In addition, the trend of Malmquist and $T C$ is similar, indicating that green innovation efficiency is dominated by technological progress instead of technological efficiency. This outcome may be related to all regions actively implement the development requirements of national "energy conservation and emission reduction", vigorously develop innovative technologies and new energy industry, rigidly curb the emission of industrial three wastes.

The aforementioned five external environmental variables have different impacts on different input slacks. The measurement of green innovation efficiency contains the influence of the external environment and statistical noise, which conceals the true value of green innovation efficiency. This result is basically consistent with our hypothesis. Thus, we substitute the adjusted input data into the same model again to obtain the real green innovation efficiency.

Except for Northeast and Southwest, SEC of the other six economic areas are all less than 1, which implies that the main reason for low EC is low $S E C$. Therefore, in order to improve the green innovation efficiency in Eight Comprehensive Economic Areas, improving the SEC should be firstly considered.

The results are supportive of understanding the reasons for low green innovation efficiency in Eight Comprehensive Economic Areas. According to the empirical analysis results, several treatment strategies to improve the green innovation efficiency can be proposed.

Different treatment policies should be formulated for each economic area. For Northeast, the industrial 
transformation and upgrading of the old industrial base should proceed toward modern industries in a tech-driven and eco-friendly manner to completely enhance green innovation efficiency. At the same time, constantly increase of proportion of high-tech industry and modern service industry should not be ignored. North coast ought to give full play to the scientific and technological innovation potential of core cities, shape the growth pole of green innovation under the new normal, and guide the advancement of green innovation efficiency of surrounding cities. For Northwest, Middle Yangtze River and Middle Yellow River, the awareness of resource conservation and the ability of independent innovation are indispensable. Meanwhile, raising the environmental standards and market entry threshold, giving priority to industries with high technology contents and low pollution level when these regions undertake the external industrial transfer. Due to the large number of industrial enterprises, it is necessary for East coast and South coast to optimize investment in environmental protection, vigorously advocate independent research and development. Via green innovation technology to alleviate the contradiction between economy and environment. For Southwest, it should strength the development and introduction of green innovation technology, make full use of resources endowments, speed up the formation of intensive and large-scale "low emission and high recycling" industries.

For the coordinated development of green innovation in Eight Comprehensive Economic Areas, the regional coordinated development as the core strategy needs to be paid enough attention. First of all, every economic area is supposed to break through the administrative barriers among regions, strengthen the regional internal cooperation, promote the free flow of green innovation elements, and realize the sharing of knowledge and technology. Secondly, the value of SEC in most economic regions is low, implying that there is a large amount of redundancy in $R \& D$ and energy input. Hence, it is of great significance for government to optimize organizational management and innovation system, adjust the proportion of input-output scale, and facilitate the utilization efficiency of green innovation resources. Thirdly, it is particularly significant to give full play to the geographical proximity advantage of Eight Comprehensive Economic Areas. The regions with high green innovation efficiency are supposed to play a radiating and leading role in the surrounding economic areas based on their own advantages. While the economic areas with low green innovation efficiency ought to raise environmental standards and market entry barriers, priority is given to industries with high technological content and low pollution levels, so as to continuously narrow the gap with economic areas of higher green innovation efficiency. Finally, the coordinated development of green innovation in Eight Comprehensive Economic Areas can be realized.

\section{Conclusions}

This research provides a fuller understanding of regional green innovation efficiency. To this extent, it is possible to advance knowledge of the coordinated development of green innovation in Eight Comprehensive Economic Areas, which generates more definitive conclusions. Based on the panel data of 30 provinces and cities in China from 2011 to 2018, this paper constructs a regional green innovation efficiency measurement model excluding external environment and stochastic disturbance. In this capacity, the main conclusions can be highlighted:

(1) The green innovation efficiency increases as a whole, and benefiting from the national "western development strategy", the green innovation efficiency of South coast, Northwest and Southwest are ahead of the country.

(2) The external environment and stochastic disturbance have a significant impact on regional green innovation efficiency throughout the study period. Specifically speaking, the improvement of ED, FDI and $E R$ will trigger the redundancy of innovation resources and decrease of the utilization rate. Additionally, the more transactions in technology market, the higher the efficiency of innovation resources utilization.

(3) The improvement of green innovation efficiency is mainly due to the improvement of $T C$ instead of $E C$. Furthermore, the basic reason for low $E C$ is low $\mathrm{S} E C$. According to the different causes of low EC, Eight Comprehensive Economic Areas are classified into four categories utilizing $P E C-S E C$ matrix, each area with different strategic opportunities to enhance green innovation efficiency.

(4) After eliminating the influence of external environment and stochastic disturbance, it is discovered that the green innovation efficiency obtained from the original Malmquist index is overestimated. The national average value of green innovation efficiency drops from 1.105 to 1.047, and Northwest and Middle Yellow River decreases 5 ranks and increases 3 ranks, respectively. It shows that the green innovation efficiency in two regions is greatly affected by external environmental factors, the slight change of resource input can lead to the obvious fluctuation of green innovation efficiency.

\section{Acknowledgements}

This research is supported by the Key Projects of Soft Science Research in Shanghai with the title "Research on Radiation Effect and Countermeasure of Shanghai Science and Technology Creation Center under the Integration Strategy of Yangtze River Delta" (19692108000). 


\section{Conflict of Interest}

The authors declare no conflict of interest

\section{References}

1. GARCÍA-MACHADO J.J., MARTÍNEZ-ÁVILA M. Environmental Performance and Green Culture: The Mediating Effect of Green Innovation. An Application to the Automotive Industry. Sustainability, 11 (18), 2019.

2. ZHANG J., LIU Y., CHANG Y., ZHANG L.X. Industrial eco-efficiency in China: A provincial quantification using three-stage data envelopment analysis. J. Clean. Prod., 143, 238, 2017.

3. GUAN D., HUBACEK K., WEBER C.L., PETER G.P., REINER D.M. The drivers of Chinese $\mathrm{CO}_{2}$ emissions from 1980 to 2030. Global Environ. Change, 18, 626, 2008.

4. GUO Y., XIA X., ZHANG S., ZHANG D. Environmental Regulation, Government R\&D Funding and Green Technology Innovation: Evidence from China Provincial Data. Sustainability, 10 (4), 2018

5. ZHAO H., GUO S., ZHAO H. Provincial energy efficiency of China quantified by three-stage data envelopment analysis. Energy, 166, 96, 2019.

6. XINHUA NEWS AGENCY. Xi Jinping: secure a decisive victory in building a moderately prosperous society in all respects, strive for the great success of socialism with Chinese characteristics for a new era -report at the19th CPC National Congress. Available online: http://www.gov. cn/zhuanti/2017-10/27/content 5234876.htm(accessed on 27 $7^{\text {th }}$ October,2017).

7. CHEN Y.S., WANG C., CHEN Y.R., LO W.Y., CHEN K.L. Influence of Network Embeddedness and Network Diversity on Green Innovation: The Mediation Effect of Green Social Capital. Sustainability, 11 (20), 2019.

8. ATTAHIRU Y.B., AZIZ M.M.A., KASSIM K.A., SHAHID S., WAN ABU BAKAR W.A., NSASHRUDDIN T.F., RAHMAN F.A., AHAMED M.I.A review on green economy and development of green roads and highways using carbon neutral materials. Renewable Sustainable Energy Reviews, 101, 600, 2019.

9. LIU S.X. Innovation design: made in China 2025. Design Management Review, 27, 52, 2016.

10. SUN Y., BI K., YIN S. Measuring and Integrating Risk Management into Green Innovation Practices for Green Manufacturing under the Global Value Chain. Sustainability, 12, 545, 2020 .

11. NOAILLY J., RYFISCH D. Multinational firms and the internationalization of green R\&D: A review of the evidence and policy implications. Energy Policy, 83, 218, 2015.

12. LEAL-MILLÁN A., LEAL-RODRÍGUEZ A.L., ALBORT-MORANT G. Green Innovation. In: Carayannis E. (eds) Encyclopedia of Creativity, Invention, Innovation and Entrepreneurship. Springer, New York, NY, 2017.

13. CONCEIÇÃO P., HEITOR M.V., VIEIRA P.S. Are environmental concerns drivers of innovation? Interpreting Portuguese innovation data to foster environmental foresight. Technol. Forecast. Soc. Change, 73, 266, 2006.

14. FANG Z., BAI H., BILAN Y. Evaluation Research of Green Innovation Efficiency in China's Heavy Polluting Industries. Sustainability, 12 (146), 2019.
15. OECD. Sustainable Manufacturing and Eco-Innovation: Framework, Practice and Measurement-Synthesis Report. Paris: OECD, 2009.

16. AGUILERA-CARACUEL J., ORTIZ-DE-MANDOJANA N. Green innovation and financial performance an institutional approach. Organ Environ., 26 (4), 365, 2013.

17. WICS, 2000. First corporate plan, 2000-2003. The Water Industry Commissioner for Scotland.

18. HUANG Z., LIAO G., LI Z. Loaning scale and government subsidy for promoting green innovation. Technological Forecasting Social Change, 144, 148, 2019.

19. FENG Y., ZHONG S., LI Q., ZHAO X., DONG X. Ecological well-being performance growth in China (1994-2014): From perspectives of industrial structure green adjustment and green total factor productivity. J. Clean. Prod., 236, 13, 2019.

20. LIU G.T., WANG B., CHENG Z.X., ZHANG N. The drivers of China's regional green productivity, 1999-2013. Resources Conservation and Recycling, 153, 14, 2020.

21. HOU B., WANG B. DU M., ZHANG N. Does the $\mathrm{SO}_{2}$ emissions trading scheme encourage green total factor productivity? An empirical assessment on China's cities. Environ Sci Pollut Res, 27 (12), 1, 2019.

22. LI W., XI Y.Q., WU F.M., MASOUD M, LIU S.Q. Green development performance of water resources and its economic-related determinants. J. Clean. Prod., 239, 11, 2019.

23. CHEN B., SINTOV N. Bridging the gap between sustainable technology adoption and protecting natural resources: Predicting intentions to adopt energy management technologies in California. Energy Research \& Social Science, 22, 210, 2016

24. DU J.L., LIU Y., DIAO W.X. Assessing Regional Differences in Green Innovation Efficiency of Industrial Enterprises in China. Int. J. Env. Res. Public Health, 16, 23, 2019.

25. CHEN Y.S., LAI S.B., WEN C.T. The influence of green innovation performance on corporate advantage in Taiwan. Journal of Business Ethics, 67, 331, 2006.

26. MARTELO-LANDROGUEZ S., ALBORT-MORANT G., LEAL-RODRÍGUEZ A.L., RIBEIRO-SORIANO B. The Effect of Absorptive Capacity on Green Customer Capital under an Organizational Unlearning Context. Sustainabilty, 10 (1), 265, 2018.

27. ZHANG X., XU B. R\&D Internationalization and Green Innovation? Evidence from Chinese Resource Enterprises and Environmental Enterprises. Sustainability, 11 (24), 2019.

28. BI K., HUANG P., WANG X. Innovation performance and influencing factors of low-carbon technological innovation under the global value chain: A case of Chinese manufacturing industry. Technol. Forecast. Soc. Change, 111, 275, 2016

29. LI H., HE F., DENG G.J. How does Environmental Regulation Promote Technological Innovation and Green Development? New Evidence from China. Pol.J.Environ. Stud., 29 (1), 689, 2020.

30. AMORE M.D., BENNEDSEN M. Corporate governance and green innovation. J. Environ. Econ. Manage., 75, 54 2016.

31. HU S.M., LIU S.L. Do the coupling effects of environmental regulation and R\&D subsidies work in the development of green innovation? Empirical evidence from China. Clean Technologies and Environmental Policy, 21, 1739, 2019. 
32. LI P.S., CHEN Y.Y. The Influence of Enterprises' Bargaining Power on the Green Total Factor Productivity Effect of Environmental Regulation-Evidence from China. Sustainability, 11 (18), 20, 2019.

33. SUN Z.Y., ZHANG W.W. Do government regulations prevent greenwashing? An evolutionary game analysis of heterogeneous enterprises. J. Clean. Prod., 231, 1489, 2019.

34. MA W., ZHANG R., CHAI S. What Drives Green Innovation? A Game Theoretic Analysis of Government Subsidy and Cooperation Contract. Sustainability, 11 (20), 2019.

35. FENG Z., ZENG B., MING Q. Environmental Regulation, Two-Way Foreign Direct Investment, and Green Innovation Efficiency in China's Manufacturing Industry., 15, 2292, 2018.

36. CUI H.R., WANG H.R., ZHAO Q.Z. Which factors stimulate industrial green total factor productivity growth rate in China? An industrial aspect. Greenhouse GasesScience and Technology, 9, 505, 2019.

37. MIAO C.L., FANG D.B., SUN L.Y., LUO Q.L. Natural resources utilization efficiency under the influence of green technological innovation. Resources Conservation and Recycling, 126, 153, 2017.

38. DENG J.Q., ZHANG N., AHMAD F., DRAZ M.U. Local Government Competition, Environmental Regulation Intensity and Regional Innovation Performance: An Empirical Investigation of Chinese Provinces. Int. J. Env. Res. Public Health, 16, 17, 2019.

39. SIMÕES P., MARQUES R. Influence of regulation on the productivity of waste utilities. What can we learn with the Portuguese experience? Waste Management. 32 (6), 1266, 2012.

40. WOO C., CHUNG Y., CHUN D., SEO H., HONG S. The static and dynamic environmental efficiency of renewable energy: A Malmquist index analysis of OECD countries. Renewable and Sustainable Energy Reviews, 47, 367, 2015.

41. MAKRIDOU G., ANDRIOSOPOULOS K., DOUMPOS M., ZOPOUNIDIS C. Measuring the efficiency of energyintensive industries across European countries. Energy Policy, 88, 573, 2016.

42. LUO Q., MIAO C., SUN L., MENG X.N., DUAN M.M. Efficiency evaluation of green technology innovation of China's strategic emerging industries: An empirical analysis based on Malmquist-data envelopment analysis index. J. Clean. Prod., 238, 117782, 2019.

43. FENG M., LI X. Evaluating the efficiency of industrial environmental regulation in China: A three-stage data envelopment analysis approach. J. Clean. Prod., 242, 118535, 2020.

44. XIE B.C., DUAN N., WANG Y.S. Environmental efficiency and abatement cost of China's industrial sectors based on a three-stage data envelopment analysis. J. Clean. Prod., 153, 626, 2017.

45. AO Y. Study on Green Development Performance and Influencing Factors in Eight Comprehensive Economic Areas of China. The Journal of Quantitative \& Technical Economics, 36, 3, 2019.

46. XIE R.H., YUAN Y.J., HUANG J.J. Different Types of Environmental Regulations and Heterogeneous Influence on "Green" Productivity: Evidence from China. Ecolog. Econ., 132, 104, 2017.
47. SHEN N., LIAO H., DENG R., WANG Q. Different types of environmental regulations and the heterogeneous influence on the environmental total factor productivity: Empirical analysis of China's industry. J. Clean. Prod., 211, 171, 2019.

48. CHARNES A., COOPER W.W., RHODES E. Measuring the efficiency of decision making units. European Journal of Operational Research, 2, 429, 1978.

49. CHARNES A., COOPER W.W., SEIFORD L., STUTZ J. A multiplicative model for efficiency analysis. Socioecon. Plann. Sci., 16, 223, 1982.

50. FÄRE R., GROSSKOPF S., NORRIS M., ZHANG Z. Productivity growth, technical progress, and efficiency change in industrialized countries. The American Economic Review, 84, 66, 1994.

51. FRIED H.O., LOVELL C.K., SCHMIDT S.S., YAISAWARNG S. Accounting for environmental effects and statistical noise in data envelopment analysis. J. Productiv. Anal., 17, 157, 2002.

52. JONDROW J., KNOX LOVELL C.A., MATEROV I.S.,SCHMIDT P. On the estimation of technical inefficiency in the stochastic frontier production function model. J. Econometrics, 19, 233, 1982.

53. NBSC. China Statistical Yearbook; National Bureau of Statistics of People's Republic of China (NBSC): Beijing,China, 2019.

54. NBSC. China Science and Technology Statistical Yearbook; National Bureau of Statistics of People's Republic of China (NBSC): Beijing, China, 2019.

55. NBSC. China Environmental Statistical Yearbook; National Bureau of Statistics of People's Republic of China (NBSC): Beijing,China, 2019.

56. LV Y., XIE Y., LOU X. Study on the Space-time Transition and Convergence Trend of China's Regional Green Innovation Efficiency. The Journal of Quantitative \& Technical Economics, 37, 78, 2020.

57. XU X.G.,WANG Y., TAO L.Comprehensive evaluation of sustainable development of regional constuction industry in China. J. Clean. Prod., 211, 1078, 2019.

58. DINDA S. Environmental Kuznets curve hypothesis: a survey. Ecolog. Econ., 49, 431, 2004.

59. YUE S., YANG Y., HU Y. Does foreign direct investment affect green growth? Evidence from China's experience. Sustainability, 8, 158, 2016.

60. PORTER M.E., VAN DER LINDE C. Toward a New Conception of the Environment-Competitiveness Relationship J. Econ. Perspect., 9, 97, 1995.

61. BITENCOURT C.C., DE OLIVEIRA SANTINI F., ZANANDREA G., FROEHLICH C., LADEIRA W. J.Empirical generalizations in eco-innovation: A metaanalytic approach. J. Clean. Prod., 245, 142020.

62. BOYD G.A., MCCLELLAND J.D. The impact of environmental constraints on productivity improvement in integrated paper plants. J. Environ. Econ. Manage., 38, 121, 1999.

63. CHENG Y.Y., SHAO T.Y., LAI H.L., SHEN M.H.,LI Y. Total-Factor Eco-Efficiency and Its Influencing Factors in the Yangtze River Delta Urban Agglomeration, China. Int. J. Env. Res. Public Health, 16, 14, 2019. 